\title{
Active surveillance for prostate cancer-will the discoveries of the last 5 years change the future?
}

\author{
Monique J. Roobol \\ Department of Urology, Erasmus University Medical Center, Rotterdam, The Netherlands \\ Correspondence to: Prof. Dr. Monique J. Roobol. Department of Urology, Erasmus University Medical Center, Rotterdam, The Netherlands. \\ Email: m.roobol@erasmusmc.nl.
}

Submitted Oct 08, 2020. Accepted for publication Oct 19, 2020.

doi: $10.21037 /$ tau-20-1321

View this article at: http://dx.doi.org/10.21037/tau-20-1321

Active surveillance as treatment option for prostate cancer (PCa) was developed to counteract the harm of so-called overdiagnosis. This is the detection [mostly driven by prostate-specific antigen (PSA) screening] of low-risk PCa which without diagnosis and treatment would never cause any harm to a patient. Per 100 men invited for PSA based screening, an estimated 5 men are unnecessarily diagnosed to avoid one man dying from PCa (1). Overdiagnosis, besides from the effects on (psychological) health of finding a cancer, would be less problematic if not subsequently most of these cancers are being treated (overtreatment), resulting in side effects and a considerable reduction of quality of life $(2,3)$. With active surveillance, men likely to have an overdiagnosed cancer are not directly treated but instead monitored and only to switch to active treatment in the case of tumor reclassification (signs of higher risk disease). But in order for active surveillance to be effective in reducing the harms of screening it must be able to select men likely to have overdiagnosed cancer at entrance, selectively filter out those with signs of more aggressive disease during follow-up, and do so before the tumor becomes beyond the window of curability (in which case the early diagnosis would be in vain). All this should be achieved without itself being too demanding on a patient's health. These prerequisites represent an enormous challenge.

The first experiences of active surveillance were reported in $2002(4,5)$. Active surveillance was applied to men diagnosed with a so-called low risk PCa defined as localized (max cT2A), Gleason score $3+3$, and PSA levels below $10 \mathrm{ng} / \mathrm{mL}$. Monitoring was done according to fixed schedules like, e.g., the PRIAS schedule (www.prias-project. org, see Figure 1) where PSA testing, rectal examinations and confirmatory biopsies are done according to a onesize-fits all fixed schedule. Long-term results of these active surveillance cohorts are good with 10- to 15 -year metastasis free and cancer-specific survival rates above $98 \%$ (6).

These long-term outcomes are based on men considered to be diagnosed with a low-risk PCa on the basis of random systematic biopsies. It is commonly known that this biopsy technique is subject to sampling error including a false negative biopsy or incorrect risk stratification due to under sampling or the detection of clinically insignificant disease as a result of over-sampling. The false negative rate exceeds $30 \%$ in some series. Under sampling of the prostate occurs in up to $30 \%$ of cases and leads to clinically significant tumors being missed on initial biopsy $(7,8)$. Hence, it is likely that many of the low risk PCa inclusions on active surveillance in those early days where in fact intermediate or high risk $\mathrm{PCa}$.

The last 5 to 10 years the PCa diagnostic and surveillance landscape has considerably changed. First, the work-up before referral for prostate biopsy has been adapted. For a long time, referral for biopsy was based on a PSA test result considered as elevated (i.e., $\geq 3.0$ or $\geq 4.0 \mathrm{ng} / \mathrm{mL}$ ) often in combination with the result of a digital rectal examination (DRE). Current guideline recommendations advise to perform a so-called reflex test before referring for imaging and/ or biopsy. This means that in those men with an elevated PSA level additional testing is recommended to exclude conditions like, e.g., benign prostatic hypertrophy (BPH) and/or prostatitis, both known to also affect the serum PSA level. Reflex testing can be done by, e.g., repeating the PSA test and/or include in the decision-making process information of additional biomarkers or other clinical data 

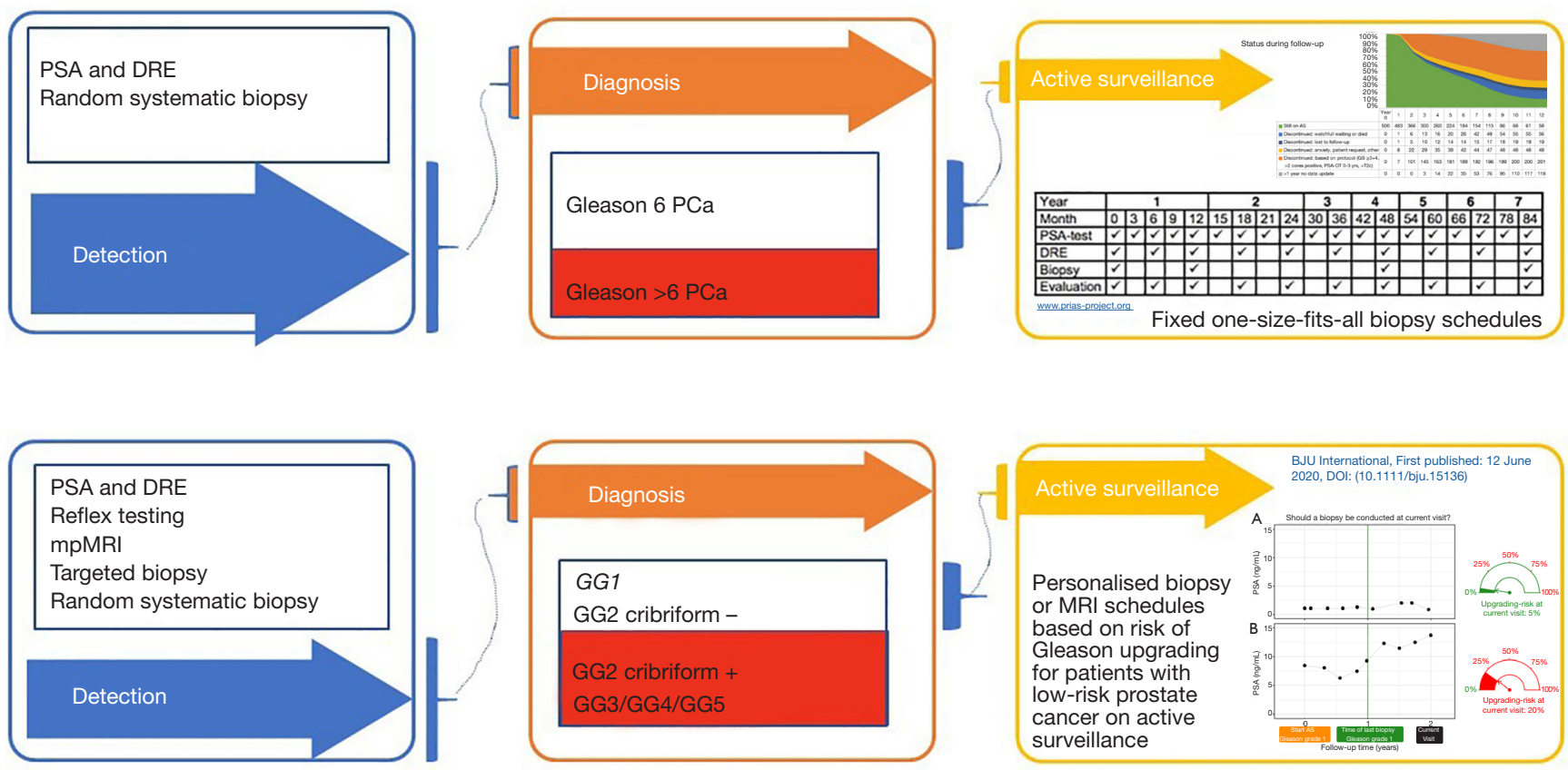

Figure 1 Identification, detection and active surveillance according to a one-size-fits-all approach (traditional, upper part of the figure) and an individual dynamic risk-based approach (future, lower part of the figure). PSA, prostate-specific antigen; DRE, digital rectal examination.

(e.g., prostate volume) often combined into a nomogram. The resulting individual risk assessment is then the basis for the decision to pursue for further testing. Implementation of this so-called individual multivariable risk stratification process leads to a decrease of unnecessary biopsies and a reduction of overdiagnosed PCa ranging from $14-83 \%$ and $10-87 \%$ respectively, depending on the setting and chosen strategy (9). As such, wide spread implementation of a multivariable risk based diagnostic approach will affect the number of men eligible for active surveillance.

Second, also the method of diagnosis changed considerably with the introduction of the multi-parametric magnetic resonance imaging (mpMRI) in combination with targeted biopsy in case of suspicious lesions (the MRI pathway). In a recent Cochrane review, it became clear that the MRI pathway outperforms the random systematic biopsy approach in correctly identifying clinically significant $\mathrm{PCa}$, reducing unnecessary biopsy procedures and overdiagnosis (8). Of note, data also showed that the MRI pathway also misses men with clinically significant PCa, which feeds the still ongoing debate of whether to omit the additional systematic biopsy $(10,11)$.

Third, detailed pathological classification further improved the classical definition of low, intermediate and high risk PCa. Grouping was merely built on the Gleason score, most commonly the three-tier Gleason score $(\leq 6,7$, $\geq 8$ ). This was changed to the 5 -tier Gleason Grade Groups including all cribriform glands and glomeruloid glands in the definition of Gleason pattern 4. This with the claim that a better risk stratification at time of diagnosis was possible and as such of value in treatment decision making (12). It has been shown that patients with Gleason score 3+4=7 without cribriform growth on diagnostic biopsy have similar disease specific survival as those with Gleason score $3+3=6$, implying these patients may be potential candidates for active surveillance as well. Cribriform growth patterns are present in app 8-37\% of Gleason 3+4 and Gleason 4+3 PCa cases respectively (13).

Finally, it becomes clear that the existing (fixed) surveillance protocols need to be changed to (I) accommodate the mpMRI and (II) to avoid unnecessary monitoring tests and resulting early drop-out due to noncompliance. In several systematic reviews on the role of mpMRI in the active surveillance setting it becomes clear that mpMRI can play an important role in optimizing the active surveillance management strategy. The high negative predictive value of mpMRI can be exploited for the selection of men willing to opt for active surveillance. In addition, the improvement in detecting and grading of suspicious lesions and the incorporation of the mpMRI into the active 
surveillance schedule can lead to less invasive strategies for the serial monitoring of men. It must however be noted that more robust data are needed to investigate the role of mpMRI in active surveillance (14-16). Long-term data on compliance to the worldwide used fixed active surveillance schedules shows that there is a considerable, worrisome decrease in compliance with the proposed sequence of visits and tests. Detailed analyses on data from the Movember global initiative GAP-3 show that especially compliance with prostate biopsy over time drops considerably. Adherence to annual and three annual biopsy schedules dropped from $92 \%$ and $89 \%$ at 1 year after diagnosis, to $66 \%$ and $71 \%$ at 7 year after diagnosis, respectively (17). In addition to non-compliance, there is also concern about the drop-out rate. Data from PRIAS, reflecting real life clinical practice worldwide show that more than half of men initially opting for an active surveillance approach switched to invasive treatment within approximately 2 years. Almost $40 \%$ of these men did so without a clear indication (18). The clinical impact of poor biopsy adherence and early drop out warrants further investigation, but it is clear that a more dynamic and individual risk-based approach to an active surveillance management strategy is a definite need.

Coming back to the title of this manuscript the answer is yes, the discoveries of the last 5 years will change the future. In Figure 1 the "traditional" way of diagnosis and active surveillance management is depicted next to the "future" active surveillance strategy; the differences are obvious. First of all, the patient population eligible for an active surveillance strategy will change. While less Gleason Group 1 PCa cases will be detected we must realize that the Gleason Group 2 PCa cases are in fact for a large part eligible for an active surveillance approach. This because of the two reasons mentioned above. First, all historical data (with most likely a mix of low and intermediate risk PCa) show excellent longterm outcomes and second detailed pathological assessment has clearly showed that a part of the Gleason Group 2 PCa cases can have an indolent course. Second the fixed schedules with repeatedly applied risky bothersome biopsy procedures are often unnecessary and unacceptable. In the near future hopefully mpMRI can be of aid in reducing the burden of active surveillance. Finally, dynamic risk prediction techniques incorporated into active surveillance management strategies will help in finding the optimal balance between the burden of monitoring while on active surveillance and the risk of missing signs of disease progression. The first models show encouraging results and the time has come to prospectively validate this approach (19-22).
It is clear that active surveillance will and must change to be able to incorporate latest developments in diagnosis and prognosis and to assure that indeed the active surveillance management strategy will be acceptable for all patients, ensuring high compliance. The latter is necessary for active surveillance to meet the expectation of reducing harm from overdiagnosis.

\section{Acknowledgments}

Funding: None.

\section{Footnote}

Provenance and Peer Review: This article was commissioned by the Guest Editors (Mieke Van Hemelrijck and Netty Kinsella) for the series "Expectant Management in Genitourinary Malignancies (Prostate, Bladder, Kidney)" published in Translational Andrology and Urology. The article did not undergo external peer review.

Conflicts of Interest: The author has completed the ICMJE uniform disclosure form (available at http://dx.doi. org/10.21037/tau-20-1321). The series "Expectant Management in Genitourinary Malignancies (Prostate, Bladder, Kidney)" was commissioned by the editorial office without any funding or sponsorship. MJR serves as an unpaid Associate Editor-in-Chief of Translational Andrology and Urology from Jan 2020 to Dec 2021.

Ethical Statement: The author is accountable for all aspects of the work in ensuring that questions related to the accuracy or integrity of any part of the work are appropriately investigated and resolved.

Open Access Statement: This is an Open Access article distributed in accordance with the Creative Commons Attribution-NonCommercial-NoDerivs 4.0 International License (CC BY-NC-ND 4.0), which permits the noncommercial replication and distribution of the article with the strict proviso that no changes or edits are made and the original work is properly cited (including links to both the formal publication through the relevant DOI and the license). See: https://creativecommons.org/licenses/by-nc-nd/4.0/.

\section{References}

1. Heijnsdijk EA, Wever EM, Auvinen A, et al. Quality-of- 
life effects of prostate-specific antigen screening. $\mathrm{N} \mathrm{Engl} \mathrm{J}$ Med 2012;367:595-605.

2. Sanda MG, Dunn RL, Michalski J, et al. Quality of life and satisfaction with outcome among prostate-cancer survivors. N Engl J Med 2008;358:1250-61.

3. Venderbos LDF, Deschamps A, Dowling J et al. Europa Uomo Patient Reported Outcome Study (EUPROMS): Descriptive Statistics of a Prostate Cancer Survey from Patients for Patients. Eur Urol Focus 2020. [In press].

4. Choo R, Klotz L, Danjoux C, et al. Feasibility study: watchful waiting for localized low to intermediate grade prostate carcinoma with selective delayed intervention based on prostate specific antigen, histological and/or clinical progression. J Urol 2002;167:1664-9.

5. Carter HB, Walsh PC, Landis P, et al. Expectant management of nonpalpable prostate cancer with curative intent: preliminary results. J Urol 2002;167:1231-4.

6. Shill DK, Roobol MJ, Ehdaie B, et al. Active Surveillance for Prostate Cancer. Transl Androl Urol 2020.

7. Bjurlin MA, Taneja SS. Standards for prostate biopsy. Curr Opin Urol 2014;24:155-61.

8. Drost FH, Osses DF, Nieboer D, et al. Prostate MRI, with or without MRI-targeted biopsy, and systematic biopsy for detecting prostate cancer. Cochrane Database Syst Rev 2019;4:CD012663.

9. Osses DF, Roobol MJ, Schoots IG. Prediction Medicine: Biomarkers, Risk Calculators and Magnetic Resonance Imaging as Risk Stratification Tools in Prostate Cancer Diagnosis. Int J Mol Sci 2019;20:1637.

10. Exterkate L, Wegelin O, Barentsz JO, et al. Is There Still a Need for Repeated Systematic Biopsies in Patients with Previous Negative Biopsies in the Era of Magnetic Resonance Imaging-targeted Biopsies of the Prostate? Eur Urol Oncol 2020;3:216-23.

11. Dell'Oglio P, Stabile A, Soligo M, et al. There Is No Way to Avoid Systematic Prostate Biopsies in Addition to Multiparametric Magnetic Resonance Imaging Targeted Biopsies. Eur Urol Oncol 2020;3:112-8.

12. Epstein JI, Egevad L, Amin MB, et al. The 2014

Cite this article as: Roobol MJ. Active surveillance for prostate cancer-will the discoveries of the last 5 years change the future? Transl Androl Urol 2021;10(6):2828-2831. doi: 10.21037/ tau-20-1321
International Society of Urological Pathology (ISUP) Consensus Conference on Gleason Grading of Prostatic Carcinoma: Definition of Grading Patterns and Proposal for a New Grading System. Am J Surg Pathol 2016;40:244-52.

13. Kweldam CF, Kümmerlin IP, Nieboer D, et al. Diseasespecific survival of patients with invasive cribriform and intraductal prostate cancer at diagnostic biopsy. Mod Pathol 2016;29:630-6.

14. Fascelli M, George AK, Frye T, et al. The role of MRI in active surveillance for prostate cancer. Curr Urol Rep 2015;16:42.

15. Giganti F, Moore CM. Magnetic resonance imaging in active surveillance-a modern approach. Transl Androl Urol 2018;7:116-31.

16. Stavrinides V, Giganti F, Emberton M, et al. MRI in active surveillance: a critical review. Prostate Cancer Prostatic Dis 2019;22:5-15.

17. Kalapara AA, Verbeek JFM, Nieboer D, et al. Adherence to Active Surveillance Protocols for Low-risk Prostate Cancer: Results of the Movember Foundation's Global Action Plan Prostate Cancer Active Surveillance Initiative. Eur Urol Oncol 2020;3:80-91.

18. Drost FH, Rannikko A, Valdagni R, et al. Can active surveillance really reduce the harms of overdiagnosing prostate cancer? A reflection of real life clinical practice in the PRIAS study. Transl Androl Urol 2018;7:98-105.

19. Tomer A, Rizopoulos D, Nieboer D, et al. Personalized Decision Making for Biopsies in Prostate Cancer Active Surveillance Programs. Med Decis Making 2019;39:499-508.

20. Nieboer D, Tomer A, Rizopoulos D, et al. Active surveillance: a review of risk-based, dynamic monitoring. Transl Androl Urol 2018;7:106-15.

21. Tosoian JJ, Carter HB. Risk Stratification in Active Surveillance: A Dynamic, Ever-Evolving Practice. Eur Urol 2018;73:713-4.

22. Denton BT, Hawley ST, Morgan TM. Optimizing Prostate Cancer Surveillance: Using Data-driven Models for Informed Decision-making. Eur Urol 2019;75:918-9. 